\title{
Vida Especial: Um jogo para a promoção do aprendizado e da conscientização sobre o Transtorno do Espectro Autista
}

\author{
Beatriz de Brito Santana ${ }^{1}$, Claudia Pinto Pereira ${ }^{1,2}$ \\ ${ }^{1}$ Engenharia de Computação - Universidade Estadual de Feira de Santana (UEFS) \\ Feira de Santana - BA - Brasil \\ ${ }^{2}$ Programa de Pós-Graduação em Ciência da Computação \\ Universidade Estadual de Feira de Santana (UEFS) - Feira de Santana - BA - Brasil \\ beatrizbritosantana@gmail.com, claudiap@uefs.br
}

\begin{abstract}
The Autism Spectrum Disorder (ASD) is a disorder that affects individuals in multiple ways. Nowadays, it is already possible to find several learning tools that aim to assist the development of these people, helping them in their independence and autonomy. On the other hand, it is possible to verify a deficit in relation to tools that promote the awareness of neurotypical people on ASD. The Vida Especial (in English, Special Life) game is a tool for the Android platform, which seeks to bring to light information about ASD, with the aim of generating an attitudinal awareness in neurotypical people, clarifying meaningful and recurring information about the disorder.
\end{abstract}

Resumo. O Transtorno do Espectro Autista (TEA) é um transtorno que afeta os indivíduos em múltiplos aspectos. Atualmente, já é possível encontrar diversas ferramentas de aprendizado, voltadas para auxiliar o desenvolvimento dessas pessoas, ajudando-as na independência e maior autonomia. Em contrapartida, é possível notar um déficit em relação às ferramentas que promovam a conscientização de pessoas neurotípicas sobre o tema. O jogo Vida Especial é uma ferramenta para a plataforma Android, que busca trazer à luz informações sobre o TEA, com o objetivo de gerar uma conscientização atitudinal em pessoas neurotípicas, esclarecendo pontos importantes e recorrentes sobre o transtorno.

\section{Introdução}

De Ajuriaguerra [de Ajuriaguerra 1977] descreve o autismo como uma perda de contato com a realidade, que traz como consequência um nível relevante de dificuldade ou impossibilidade referente à comunicação [Gadia et al. 2004]. Esse transtorno vem sendo discutido por cientistas e outros profissionais da área, que tentam identificar uma possível origem e características do espectro que possam ser utilizadas no momento do diagnóstico [Nascimento 2018]. Porém, mesmo sendo um tema que, visivelmente, vem ganhando espaço na mídia e nas rodas de conscientização, ainda existe uma grande "nuvem" de preconceito rodando esse assunto e a falta de informação pode estar, até mesmo, entre pais e educadores.

No contexto escolar, Teixeira e Ramos [Teixeira and Ramos 2015] destacam que o professor pode utilizar os recursos digitais para trabalhar práticas pedagógicas que, 
nesta circunstância, auxiliam na construção do conhecimento, ajudando a desenvolver competências cognitivas da criança. Esse é potencialmente um cenário apropriado para aplicação da educação inclusiva, sendo um primeiro passo para extinguir conceitos errôneos sobre pessoas com o espectro autista, por exemplo, aproximando o estudante do tema e trazendo à luz informações que ajudem a criar uma nova perspectiva em relação a este ou outros transtornos ou deficiências.

Esses conteúdos digitais podem vir no formato dos chamados serious games ou jogos sérios. Os jogos sérios não se destinam somente ao entretenimento, mas buscam, em sua essência, propiciar a educação de maneira lúdica. Macedo [Macedo 2019] afirma que uma das características essenciais para a utilização de jogos desse tipo é a motivação que é gerada durante o aprendizado, levando a absorção de conceitos de forma fácil e com rápida assimilação.

Diante desse contexto, o presente trabalho tem como objetivo utilizar os conceitos de jogo sério para promover a conscientização e o aprendizado sobre o autismo para a sociedade de uma maneira geral. O jogo "Vida Especial" é uma solução destinada a pessoas neurotípicas para o aprendizado sobre o espectro autista e sobre como as pessoas com autismo podem ter o seu dia-a-dia afetado por esse transtorno. A ferramenta contará a história do personagem Erick, uma criança que possui o espectro. O jogador terá contato direto com um narrador textual, que o conduz pela história, passando por cenários aparentemente comuns da vida cotidiana, como, por exemplo, se arrumar para ir à escola, tarefas que para uma pessoa com TEA podem se tornar algo extremamente estressante e incômodo. A partir daí, a história seguirá apresentando esses incômodos e solicitando que sejam realizadas ações para melhorar o ambiente para Erick. O jogo foi validado positivamente por um grupo de pais de crianças com TEA, a partir de uma análise quali-quanti.

\section{Fundamentação Teórica}

\subsection{Transtorno do Espectro Autista (TEA)}

O Manual Diagnóstico e Estatístico de Transtornos Mentais, 5a edição (DSM-5), traz, como um dos critérios diagnósticos para a identificação do Transtorno do Espectro Autista (TEA), a existência de persistentes déficits na comunicação e interação social em diversos cenários e contextos [APA 2014]. O diagnóstico não é feito de forma fácil e, até mesmo entre os profissionais da saúde, não há um consenso da causa para esse transtorno [Neto et al. 2017]. Algumas pessoas podem desenvolver problemas de atenção, problemas com estímulos externos do ambiente como luz forte e/ou barulho, interesse em atividades repetitivas, sensibilidade ao toque e até crise de agressividade [de Mira Gobbo et al. 2018].

Dados publicados em 2015 pela Organização das Nações Unidas (ONU) revelam a estimativa de que 70 milhões de pessoas no mundo possuíam o espectro autista naquele momento, o que correspondia a cerca de $1 \%$ da população, sendo mais comum do que doenças como câncer, AIDS e diabetes [ONU Brasil 2015]. Uma estatística mais recente, levantada pelo CDC (Center for Disease Control and Prevention ou Centro de Controle e Prevenção de Doenças), afirma que a cada 54 crianças, 1 é diagnosticada com o autismo, sendo quatro vezes mais comum em meninos do que em meninas [Centers for disease control and prevention 2020]. Apesar desse número expressivo, 
o Transtorno do Espectro Autista é pouco discutido e rodeado de estereótipos.

Esses estereótipos também se propagam dentro das escolas, mesmo entre os próprios educadores que imaginam os indivíduos autistas como seres encapsulados em seu próprio mundo, inaptos a interagir em sociedade [Nunes et al. 2013].

Em meio a esse contexto, surgem as tecnologias que têm sido usadas como auxílio para a educação e podem se tornar aliadas para atenuar alguns comportamentos, melhorar e potencializar habilidades das pessoas que estão no espectro. Dentre as tecnologias que podem auxiliar no aprendizado estão os jogos. Conhecidos como jogos sérios, trazem do mundo do entretenimento uma ferramenta poderosa para envolver o estudante no processo de aprendizado e, até mesmo, promover a conscientização.

\subsection{Jogos e Conscientização}

De acordo com Carvalho [Carvalho 2015], os jogos são contextos com regras bem definidas, nos quais os jogadores têm objetivos e desafios claros. Macedo [Macedo 2019] completa que os jogos sérios apresentam cenários próximos da realidade, que envolvam os estudantes na construção e na ressiginificação de conceitos e conhecimentos. Entretanto, antes mesmo do surgimento destes, estudiosos do campo da educação já pesquisavam a conexão entre o brincar/jogar e o aprendizado, apontando vantagens no uso de elementos lúdicos como estratégia para se educar, e desenvolver competências cognitivas nos estudantes [Vasconcellos et al. 2017].

Segundo Cox e Bittencourt [Cox and Bittencourt 2017], a importância cognitiva de um jogo educacional está na diversidade de pesquisas que indicam que estes são capazes de desenvolver habilidades que são consideradas indispensáveis para a aprendizagem. Dentre essas habilidades, estão a atenção, a concentração, a orientação espacial, a resolução de problemas, a tomada de decisões, o trabalho colaborativo, a criatividade e outros. Essas características são alcançadas quando há um equilíbrio entre os elementos de diversão e de educação.

Em um estudo sobre o uso de jogos como instrumento de conscientização sobre o cyberbullying, [Braga et al. 2018, p. 9] afirmaram que "o uso dos jogos pode contribuir significativamente para o processo de ensino e aprendizagem, pois agregam um caráter lúdico à atividade, propiciando desafios, estabelecendo relações, possibilitando o confronto de hipóteses, de erros e de acertos e criando estratégias para aprendizagens significativas". Nesse contexto, os jogos digitais podem servir como uma ferramenta de auxílio para apresentar informações relevantes sobre os temas dessas discussões. Esse tipo de abordagem pode ser utilizado para o ensino sobre o autismo, promovendo não somente o aprendizado e a conscientização, mas também uma maior inclusão social das pessoas com o espectro autista.

\subsection{Trabalhos Relacionados}

Durante as pesquisas por trabalhos relacionados, foi encontrado um artigo sobre o uso de jogos digitais para a promoção da conscientização sobre o mundo autista, considerando o período de 2014 a 2019 e as bases descritas na metodologia. O projeto Tales of Health é um jogo do tipo storytelling, que apresenta um cenário onde o jogador é exposto a uma determinada narrativa, e onde suas decisões e escolhas durante a jogatina interferem em toda a história [Aguiar et al. 2019], criando um ambiente de escolhas conscientes. 
Para além dos jogos de conscientização voltados para os neurotípicos, encontramse, em quantidade superior, aqueles voltados para o público atípico, que objetivam auxiliar no processo de aprendizagem e socialização das pessoas autistas. Ainda que não diretamente relacionados à proposta deste artigo, apresentaremos dois deles por terem sido utilizados de alguma forma na concepção do jogo proposto. Macedo [Macedo 2019] propõe o jogo o Knowledgemon Hunters, voltado para o aprendizado e o desenvolvimento de crianças com o espectro autista a partir do uso da realidade aumentada. Neste cenário, a criança deve buscar pelo personagem do jogo para capturá-lo e assim liberar um conteúdo de aprendizagem. O objetivo é tentar reduzir o isolamento social com o uso da realidade virtual, que pode ajudar a criança a vencer o medo de sair de casa, ajudandoo no desenvolvimento social. Bastos Neto, Silva e Pereira [Neto et al. 2017] propuseram o jogo educativo Autastico, feito para auxiliar no desenvolvimento de crianças autistas, sem excluir as neurotípicas que possuam algum tipo de dificuldade de aprendizado. Foi desenvolvido um aplicativo para a plataforma mobile e permite que o jogador escolha, entre várias atividades, o que deseja fazer: desenhar formas básicas, brincar com expressões faciais ou cores.

Embora já exista uma diversidade de jogos sérios voltados para as pessoas autistas, há poucos de conscientização para o público neutorípico, se caracterizando como uma lacuna importane, no sentido de elucidar características e estratégias para lidar com pessoas do espectro e evitar preconceitos e pré-julgamentos que dificultem ainda mais suas vidas. Neste sentido, o jogo 'Vida Especial' se assemelha ao Tales of Health, e difere no design e interação, pois é um jogo mobile que traz incômodos e situações desagradáveis ao autista, que precisam da ajuda do jogador para saná-los, enquanto o Tales of Health utiliza uma plataforma de mensagens instantânea e a troca de mensagens para a interação.

\section{Metodologia}

Esse trabalho foi motivado, inicialmente, pelas reflexões e questões tratadas em duas disciplinas na matriz curricular do Curso de Engenharia de Computação: Informática na Educação e Jogos Digitais, na Universidade Estadual de Feira de Santana (UEFS). Dessa motivação, nasceu a primeira versão do jogo Vida Especial, em 2017, que contava com a existência de um cenário e foi desenvolvida para a plataforma Desktop [Santana et al. 2018].

Para aprofundar o desenvolvimento da ferramenta, como primeira etapa para a evolução do trabalho proposto, foi necessário encontrar estudos para estabelecer a base teórica. Para tanto, foi realizado um mapeamento sistemático ${ }^{1}$, nas bases da Revista Brasileira de Informática na Educação (RBIE), Simpósio Brasileiro De Informática Na Educação (SBIE), Workshop de Informática na Escola (WIE), Workshops do Congresso Brasileiro de Informática na Educação (WCBIE), Revista Eletrônica de Iniciação Científica em Computação (REIC) e Google Acadêmico, com o objetivo de identificar trabalhos que abordassem as principais características de pessoas com o TEA e como o uso de jogos sérios poderiam influenciar na conscientização atitudinal dos indivíduos em relação ao tema. Foram encontrados 40 trabalhos no total (em uma busca pelos anos de 2014 a 2019), que serviram de base teórica para os próximos passos metodológicos.

O Game Design Canvas (GDC), que já havia sido aplicado anteriormente ao pro-

\footnotetext{
${ }^{1}$ Um artigo detalhando todo este mapeamento foi submetido a um periódico e está em fase de análise
} 
jeto, foi atualizado mediante os novos objetivos. Esse framework, proposto por Sarinho [Sarinho 2017], permite visualizar aspectos importantes e centrais do projeto como o design, definições, conceitos, prototipação, controle, jogabilidade, mecânica e ambiente.

O próximo passo envolveu decidir quais sintomas e características seriam abordados na história do jogo. Como já existia a história do primeiro cenário, foi feita uma validação dos aspectos abordados, relacionando com as informações adquiridas dos estudos levantados e das descrições encontrados no DSM-5 (revisão da história do cenário 01), e ampliando as decisões para o segundo cenário (escrita da história do cenário 02). Para a refatoração do primeiro cenário e o desenvolvimento do segundo, a ferramenta utilizada foi o Godot. Todo o design e telas do jogo foram feitos usando ferramentas de design como o Adobe Photoshop, Adobe Illustrator e algumas versões semelhantes da empresa Affinity. Já as músicas utilizadas foram retiradas do site Bensound e Freesound, locais onde é possível encontrar trilhas gratuitas para uso, sendo passíveis apenas da ação de creditar o autor, ação esta que foi feita na página de créditos disponível no jogo.

Como a proposta deste projeto envolveu a melhoria do jogo, a implementação de um novo cenário e também a etapa de validação inicial desta segunda versão por pais e especialistas, foram necessárias a submissão e a aprovação do projeto pelo Comitê de Ética da instituição (CAAE n. 30873820.0.0000.0053), anteriores à validação.

Concluída a etapa de desenvolvimento, foi feito um teste piloto. $\mathrm{O}$ conceito do projeto e o produto foram exibidos para a mãe de uma criança autista e para um professor da Universidade que, além de ser pai de uma criança dentro do espectro, também possui expertise no desenvolvimento de jogos, principalmente educativos. Durante esse teste piloto, foi possível observar as primeiras impressões dos usuários, concluindo em feedbacks que foram valiosos para a melhoria do produto. Com os comentários do teste piloto, foram aplicadas melhorias na ferramenta para a geração do executável e avançou-se para a fase de avaliação. Inicialmente, a avaliação aconteceria em parceria e com a autorização da APAE (Associação de Pais e Amigos dos Excepcionais) de Feira de Santana, entretanto, por conta das limitações impostas pelo cenário atual decorrente da pandemia da COVID19, a validação foi feita por pais de autistas, de forma online, que estavam próximos do vínculo pessoal do pesquisador.

Os resultados foram obtidos a partir de uma análise quali-quantitativa, envolvendo um questionário seguindo a escala de Likert com 5 opções de resposta: discordo fortemente, discordo parcialmente, não discordo nem concordo, concordo parcialmente e concordo fortemente. Para a criação do instrumento de coleta, foi utilizado como apoio o modelo de avaliação MEEGA+ [Petri et al. 2017]. Esse modelo é usado para avaliar a qualidade de jogos educacionais e traz diversas questões pertinentes à avaliação da ferramenta, como perguntas sobre a usabilidade do jogo, aspectos da satisfação, diversão, aprendizagem percebida, entre outros. Além de questões retiradas do modelo, também foram feitas algumas perguntas de perfil e dois campos livres ao final do formulário. Com isso, foi possível verificar em quais pontos o sistema possuía falhas e quais melhorias poderiam vir a ser aplicadas. 


\section{Resultados e Discussões}

\subsection{Planejamento e Modelagem do jogo}

O processo de planejamento e modelagem da ferramenta tiveram início com a atualização do GDC proposto anteriormente, com a adição dos novos requisitos definidos após a leitura dos estudos, tais como as informações sobre os níveis de dificuldade, informação sobre o funcionamento das fases com e sem tempo, correção de nomenclaturas, entre outros.

Após a atualização do GDC, foram selecionados os sintomas e situações mais comuns do dia a dia de uma pessoa com TEA e, em seguida, feita a relação entre o cenário do jogo onde a característica seria trabalhada e o sintoma/característica em si. O primeiro cenários trabalha questões de sensibilidade à luz, sensibilidade ao barulho, incômodo com tecidos de roupas, apego por organização e/ou limpeza. Já o segundo cenário trata as questões relacionadas à manutenção da rotina, falta de noção de perigo e interação social e vida na escola.

\subsection{Telas e Interface do jogo}

O primeiro passo foi refatorar o cenário já existente e, para isso, a maioria das telas do jogo, já desenvolvido anteriormente, foi modificada. Foram executadas melhorias nos textos, diálogos e no próprio design, com correções relacionadas a erros de continuidade, entre outros. Como o projeto original não estava mais disponível, o jogo foi totalmente recriado na versão mais atual do Godot, com as adaptações necessárias para a versão mobile. Em seguida, foram criados os artefatos visuais necessários para o segundo cenário, implementando a história e desafios definidos na etapa anterior, finalizando com a tela de créditos e telas de game over personalizadas.

O jogo retrata a vida do personagem 'Erick', um garoto de 12 anos de idade, que possui o TEA. O jogador precisa acompanhar Erick durante o seu dia-a-dia, passando por situações habituais de sua vivência, auxiliando o personagem desde o momento em que ele acorda até a sua ida à escola. Nesse processo, um narrador textual é responsável por explicar ao jogador sobre a vida do Erick, além de esclarecer as características incômodas de cada fase, ensinando sobre alguns aspectos do transtorno (Figura 1).

Toda a interação é feita através de toques na tela do celular. Na cena de incômodo com barulho, o usuário precisa encontrar e clicar no fone de ouvido, disponível na mesa do personagem, no canto direito da tela, para suspender o incômodo . Quando o usuário não conclui o desafio da fase e não consegue interromper o que está causando um ambiente desconfortável para o personagem, é exibida uma tela de game over, que corresponde a um momento de crise do Erick. Nessa cena, propôs-se exibir essa situação, não agradável, porém presente na vida de uma pessoa no espectro, de uma forma um pouco mais leve, ressaltando que apesar da crise, Erick ainda pode continuar a sua jornada, ou seja, enfatizando que, apesar de um momento ruim, as pessoas não precisam temer ou se afastar do indivíduo e que, com informação, pode-se aprender a como agir nessas situações, tornando tudo mais agradável para ambos os envolvidos.

\subsection{Resultados do Teste Piloto}

Para o teste piloto, foi feita uma avaliação online, por vídeo chamada, mostrando, passo a passo, o funcionamento do jogo. A primeira entrevistada é formada em Licenciatura em 


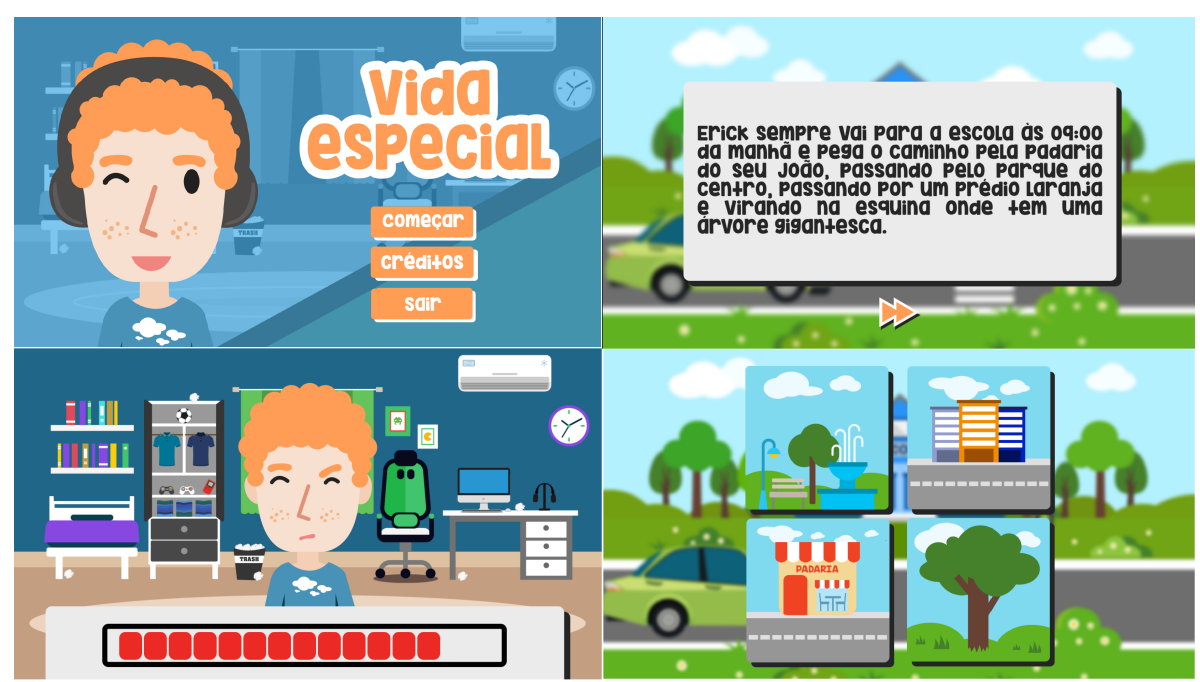

Figura 1. Na coluna à esquerda: menu inicial e fase retratando o incômodo do barulho. Coluna à direita: fase para aprendizado sobre rotina. Fonte própria, 2021

História e mãe de autista, e o segundo, um professor e pesquisador na área de Produção de Jogos Digitais da Universidade Estadual de Feira de Santana.

Levando os feedbacks em consideração e buscando tornar a experiência mais real, aproximando o jogador dos comportamentos e incômodos sentidos pelo personagem, foi feita a adição de música e alguns efeitos sonoros na ferramenta, bem como foram utilizados efeitos visuais para enfatizar o desconforto do personagem durante a cena da iluminação, por exemplo. No momento em que Erick está incomodado com a luz, a tela do jogo fica piscando; já no momento do incômodo do barulho, o jogo passou a apresentar um som alto de conversa, que vai além do volume previamente definido no aparelho do jogador. Também foi apontado pelos entrevistados que alguns objetos ficaram excessivamente pequenos para o clique nas telas estreitas dos smartphones, como, por exemplo, o fone de ouvido no canto da tela e as bolinhas de papel espalhadas pelo cenário. Para resolver essa questão, a área do clique do fone foi ampliada, assim como o tamanho das bolinhas de papel disponíveis no jogo.

Do mesmo modo, foram adicionados níveis de dificuldade. A diferença entre os níveis está entre a velocidade dos efeitos visuais, como a tela piscando no cenário do incômodo da luminosidade, já citado anteriormente; o volume do barulho de pessoas conversando no cenário do incômodo com o som; a existência de uma quantidade maior de bolinhas de papel do quarto para serem recolhidos; maior velocidade na troca do semáforo entre vermelho e verde, na cena em que o jogador deve clicar no semáforo no exato instante em que ele estiver verde; além de uma dificuldade maior na execução do jogo, levando o jogador a repetir todo o processo do começo ao se deparar com o erro, em contraponto com o nível normal, no qual é possível voltar e tentar novamente acertar àquela mesma fase.

No geral, o teste piloto serviu para captar melhorias que já puderam ser imediatamente implementadas e que, apesar de parecerem simples, trouxeram maior dinamismo ao jogo melhorando a experiência do jogador. 


\subsection{Validação da versão final do jogo}

Para a validação do jogo, foi feita a aplicação do questionário MEEGA+ (Model for the Evaluation of Educational Games). O questionário original foi adaptado, selecionando as perguntas que mais se adequavam ao propósito do jogo, ficando ao final com 39 questões, as duas primeiras de perfil; as 24 próximas $(\mathrm{Q} 3$ a Q26) referentes à usabilidade e jogabilidade; as 8 seguintes (Q27 a Q34) relacionadas ao conteúdo do jogo e seus objetivos educacionais, e as 5 demais, abertas.

Foram contatadas 25 pessoas no total, em sua maioria pais de pessoas dentro do espectro. Esse contato foi feito através do aplicativo de mensagens Whatsapp e a abordagem foi feita através de duas pessoas voluntárias, que serviram de mediadoras para divulgar sobre a ferramenta em dois grupos de pais e mães de crianças autistas. Do total contatado, apenas 9 pessoas prosseguiram com o teste até o final. Como o teste foi feito de forma assíncrona, ou seja, as informações e o jogo eram enviadas e a pessoa poderia fazer o teste e responder o questionário quando estivesse disponível, muitas pessoas alegaram não ter conseguido um tempo específico para testar o jogo, por conta dos afazeres do diaa-dia, mesmo após repetidos contatos. Esse acaba sendo mais um dos aspectos negativos causados pela pandemia, que impediu que o teste fosse realizado de forma presencial.

Em relação ao perfil dos participantes, $22,2 \%$ possuíam mais do que 50 anos, seguido por $22,2 \%$ das pessoas com faixa etária entre 40 e 50 anos; a grande maioria estava entre 25 e 39 anos e os outros $11,1 \%$, entre 18 e 24 anos. Já no questionamento sobre a relação com pessoas do espectro autista (pais ou especialistas), 88,9\% relataram ser pais de pessoas com o transtorno e apenas $11,1 \%$ respondeu ter contato direto com uma pessoa do espectro. Isso já era esperado, já que o canal principal de divulgação foi em grupos de pais. A partir daí, foram respondidas as questões.

As questões Q3 a Q26 tratavam dos aspectos de usabilidade e de jogabilidade. A usabilidade faz referência à facilidade que o usuário tem ou não de utilizar a ferramenta e a existência, ou não, de clareza nos itens visuais apresentados, ou seja, um conjunto de fatores que garantem que o usuário consiga utilizar o sistema de forma agradável. Já a jogabilidade, segundo [Medeiros 2015, p. 682], "representa o grau em que os usuários podem alcançar objetivos específicos com eficiência, eficácia e, especialmente, com satisfação e diversão em um contexto jogável de uso". Nesse contexto, os questionamentos empregados buscaram entender o nível dos itens visuais dispostos no jogo, como cores, fontes e o design em geral, agregando também itens como avaliações acerca da imersão do jogador na ferramenta, nível de diversão, atenção e facilidade de aprendizagem. Das 32 questões objetivas relacionadas ao jogo, 23 tovera, resultado positivo, oscilando em sua maior parte, entre as respostas "Concordo Fortemente" e "Concordo Parcialmente".

Ainda em relação à usabilidade e jogabilidade, algumas questões obtiveram respostas do tipo "Discordo Parcialmente", tais como as questões Q5 e Q12, que são questões que abordam o sistema do ponto de vista da atenção e imersão do usuário no jogo. Algumas pessoas também relataram não ter obtido sentimentos de eficiência e facilidade ao aprender a jogar a ferramenta (Q21 e Q23), aspecto também evidenciado em conversa informal durante o teste, quando alguns disseram não ter entendido o que deveria ser feito para avançar no jogo. Entretanto, pode-se perceber que esta dificuldade aconteceu, mais especificamente, na primeira cena do jogo, quando o usuário estava tendo o primeiro contato com o ambiente e a primeira experiência de uso, prosseguindo sem maiores dúvidas. 
Isso indica a necessidade de explicar ao usuário o funcionamento básico do jogo, que poderia ser feito com um simples tutorial exibido antes do primeiro cenário.

Foram identificadas respostas negativas do tipo "Discordo Fortemente" $(11,1 \%)$ na questões Q13 ("Me senti mais no ambiente do jogo do que no mundo real, esquecendo do que estava ao meu redor"). Essa questão aborda aspecto de imersão dentro do jogo. Este resultado poderia ser interpretado de duas formas. A primeira delas é que o jogo poderia ser considerado desinteressante e, por conta disso, o jogador não conseguiu imergir na experiência durante o uso da ferramenta, entretanto os indicadores recebidos na questão Q16 ("Me diverti com o jogo") contrapõem esse resultado, já que a maioria das pessoas optou por Concordo Fortemente $(77,8 \%)$. Por isso, a segunda interpretação, mais plausível, é que as pessoas se sentiram entretidas, porém não imergiram na experiência como acontece com jogos que utilizam recursos de realidade virtual.

As questões Q17 a Q19 reforçam que as impressões do jogo foram bem positivas, como a questão "Quando acabou, fiquei desapontado que o jogo tinha acabado (gostaria de jogar mais)" (Q17), que apresentou 88,9\% e 11,1\%, respectivamente, para"Concordo Fortemente" e "Concordo Parcialmente". Com isso, a percepção é de que o fim do jogo causou ao usuário um desapontamento, sinalizando que o participante gostaria de continuar jogando e/ou de que prendeu sua atenção. Isso se reflete na pergunta seguinte: "Eu recomendaria este jogo para meus colegas", que obteve a mesma porcentagem da questão anterior. No espaço para comentários, algumas pessoas citaram que "O jogo é maravilhoso, essencial para pessoas que ainda tenham uma visão limitada e preconceituosa acerca do autismo. Gostaria de ver mais fases" e ainda "Jogo agradável, que informa e prende o jogador, pena que foi tão curto.", ressaltando a vontade de que a ferramenta tivesse mais cenários.

Outra categoria importante, relacionada ao conteúdo disponibilizado, também obteve resultados positivos. As questões buscavam entender qual o nível de conhecimento das pessoas antes e depois do uso da ferramenta, se as informações no jogo foram apresentadas de forma clara e se as informações apresentadas contribuíram para a aprendizagem e a conscientização sobre o TEA, sendo este o principal objetivo desse projeto. Destas, a questão que teve maior variação de respostas foi a Q28: "Depois de usar o jogo eu passei a compreender mais sobre o Transtorno do Espectro Autista.". Esta pergunta se relaciona com as respostas da questão "Antes de usar o jogo eu já compreendia sobre o Transtorno do Espectro Autista" (Q27), na qual 100\% das pessoas responderam com "Concordo Fortemente". O fato de a maioria dos participantes serem pais de pessoas com o transtorno justifica o motivo de ter existido pouca contribuição para a aprendizagem, por conta da bagagem anterior sobre o assunto. Dessa forma, a Q28 obteve 33,3\% de "Concordo Fortemente"; 33,3\% de "Concordo Parcialmente" e 33,3\% para "Não discordo, nem concordo", significando que houve, ao menos, alguma contribuição para o aprendizado quanto ao TEA.

Três questões que tiveram, em sua grande maioria, respostas positivas, e que estão relacionadas com a questão do aprendizado são: "O conteúdo do jogo é relevante para os meus interesses" (Q6 com 77,8\% para Concordo Fortemente e 22,2\% para Concordo Parcialmente); "O funcionamento deste jogo está adequado ao meu jeito de aprender" (Q7, com 77,8\% para Concordo Fortemente) e "Ao passar pelas etapas do jogo senti confiança de que estava aprendendo" (Q8 com 77,8\% para Concordo Fortemente e 22,2\% 
para Concordo Parcialmente). Infere-se, a partir delas, que o conteúdo é relevante e o funcionamento do jogo adequado às expectativas de aprendizagem do público conhecedor sobre o tema e, sobretudo, reforça o objetivo principal do jogo que é o de promover o aprendizado sobre o TEA para pessoas neurotípicas. Ainda sobre o conteúdo abordado, a confiabilidade foi confirmada com a questão Q32, com $100 \%$ de votos concordantes, indicando que as informações trazidas no jogo são consistentes em relação à realidade.

Dois campos livres, foram disponibilizados um para pontos fortes do jogo e o segundo sobre críticas e sugestões. Em relação a comentários positivos, alguns foram: "As reações que sentimos em cada fase são fortes e perceptiveis aos que as pessoas com TEA devem sentir"; "O jogo é maravilhoso, essencial para pessoas que ainda tenham uma visão limitada e preconceituosa acerca do autismo. Gostaria de ver mais fases" e "A forma de veiculação da informação através do jogo; A facilidade de execução das tarefas no jogo, graças às boas instruções; Cores bem legais, meus olhos não reclamaram”.

Quanto às sugestões de melhorias coletadas, pretende-se empregá-las futuramente, como: acrescentar voz, alterar a fonte da letra para tornar mais legível, permitir a escolha de mais de m personagem, ajustar o volume do som padrão do jogo. Além disso, muitos comentários falaram sobre estender o jogo para abranger mais cenários e uma história maior.

\section{Conclusão}

Durante a construção desse projeto, as pesquisas realizadas demonstraram uma carência de tecnologias voltadas exclusivamente para a conscientização sobre o TEA. Em contrapartida, é possível encontrar diversas ferramentas que foram criadas com foco no uso por pessoas do espectro autista. Diante deste cenário, esse trabalho propôs uma ferramenta para auxiliar na conscientização e no aprendizado de pessoas neurotípicas sobre o TEA.

Com a realização de um teste mais expansivo, será possível utilizar, com mais qualidade, as orientações de avaliação de resultados propostas pelo MEEGA+, que contam com cálculos de medida de tendência central, como mediana, média e frequência de resposta, ou seja, com o uso de métodos estatísticos descritivos [Petri et al. 2017]. Mesmo com esta limitação, os resultados já obtidos apontam positivamente para o uso do jogo como ferramenta de conscientização e de aprendizado sobre o TEA e permitem identificar futuras melhorias, anteriores aos novos testes com um grupo maior de pessoas. Além das melhorias já relatadas anteriormente, outros trabalhos futuros que podem ser realizados para tornar o jogo mais atrativo e mais dinâmico é a adição de um mini-tutorial no início do jogo explicando o funcionamento, com imagens animadas que deixem o processo mais dinâmico e atrativo, e, até mesmo, pistas que possam aparecer na tela quando o jogador não conseguir avançar por muito tempo, adição de um narrador por voz e a implementação de um sistema de conquistas para que o jogador se sinta entusiasmado para repetir a experiência várias vezes, até alcançar todas as conquistas disponíveis. Isso pode trazer uma maior fixação do conteúdo abordado.

Mais a frente também desejamos publicar a ferramenta na plataforma da Google Play, algo que já poderá ser feito muito em breve visto que a ferramenta já está pronta. Foi possível validar que o conteúdo do jogo está alinhado com a realidade e que este pode vir a ser usado como uma ferramenta de aprendizado, adicionando informações sobre o mundo do autismo, até mesmo para quem já tem contato com alguém do espectro. 


\section{Referências}

Aguiar, E., Gomes, V., and Sarinho, V. (2019). Tales of health-tea: Uma proposta de storytelling digital para conscientização do transtorno do espectro do autismo. https://sol.sbc.org.br/index.php/sbcas/article/view/6260.

APA (2014). Manual diagnóstico e estatístico de transtornos mentais: Dsm 5. http://www.niip.com.br/wp-content/uploads/2018/06/Manual-Diagnosico-eEstatistico-de-Transtornos-Mentais-DSM-5-1-pdf.pdf.

Braga, K. M. M. C. B., Oliveira, P. M., Sousa, P. J., Legey, A. P., Mól, A. C., Freitas, V. G., and Trotta, L. (2018). Bullying e cyberbullying no ambiente escolar: a utilização de jogos como instrumento de conscientização, prevenção e combate a essas práticas. Revista Carioca de Ciência, Tecnologia e Educação, 3(1).

Carvalho, C. V. (2015). Aprendizagem baseada em jogos. pages 176-181.

Centers for disease control and prevention (2020). Data and statistics on autism spectrum disorder. https://www.cdc.gov/ncbddd/autism/data.html.

Cox, K. and Bittencourt, R. (2017). Estudo bibliográfico sobre o processo de construção de jogos digitais: A necessidade de sinergia entre o educar e o divertir. Revista Brasileira de Informática na Educação, 25(01):16.

de Ajuriaguerra, J. (1977). Manual de psiquiatría infantil. Masson.

de Mira Gobbo, M. R., de Barbosa, C. R. S. C., Morandini, M., Mafort, F., and Mioni, J. L. V. M. (2018). Jogo ACA para indivíduos com transtorno do espectro autista. Simpósio Brasileiro de Games e Entretenimento Digital (SBGames).

Gadia, C. A., Tuchman, R., and Rotta, N. T. (2004). Autismo e doenças invasivas de desenvolvimento. Jornal de pediatria, 80(2):83-94.

Macedo, F. T. (2019). Um jogo georreferenciado com recurso de realidade aumentada para auxiliar o aprendizado e desenvolvimento de crianças com autismo. Trabalho de conclusão de curso (bacharelado em ciências da computação), Universidade Federal Rural do Semi-Árido.

Medeiros, J. F. (2015). Avaliação de usabilidade e jogabilidade em jogos para dispositivos móveis.

Nascimento, R. S. (2018). Os beneficios da aplicacao de jogos educacionais executados por computador e dispositivos moveis no tratamento do transtorno do espectro autista. In Anais da V Escola Regional de Sistemas de Informação do Rio de Janeiro, pages 74-77, Porto Alegre, RS, Brasil. SBC.

Neto, G. D. B., Silva, G. C., and Pereira, C. P. (2017). Autastico: Jogo educativo na plataforma android para auxiliar no desenvolvimento social e cognitivo de crianças autistas. XVI SEPA - Seminário Estudantil de Produção Acadêmica, 16.

Nunes, D. R., Azevedo, M., and Schmidt, C. (2013). Inclusão educacional de pessoas com autismo no brasil: uma revisão da literatura. Revista Educação Especial, 26(47):557572.

ONU Brasil (2015). Especialistas da onu em direitos humanos pedem fim da discriminação contra pessoas com autismo. 
Petri, G., Gresse von Wangenheim, C., and Borgatto, A. (2017). Meega+: Um modelo para a avaliação de jogos educacionais para o ensino de computação. Revista Brasileira de Informática na Educação, 27:52.

Santana, B. B., Pereira, C. P., Brito, K. O., and Sarinho, V. T. (2018). Projeto vida especial: Um jogo digital para vivência de situações do transtorno do espectro autista. In SBC - Proceedings of SBGames.

Sarinho, V. T. (2017). Uma proposta de game design canvas unificado. In XVI Simpósio Brasileiro de Jogos e Entretenimento Digital (SBGames), page 141-148.

Teixeira, S. and Ramos, A. (2015). Narrativa digital no jardim de infância: motivação, dificuldades e interação presencial e online. Universidade do Minho. Centro de Competência TIC (CCTIC UM), pages 1367-1380.

Vasconcellos, M. S., Carvalho, F. G., Barreto, J. O., and Atella, G. C. (2017). As várias faces dos jogos digitais na educação. In Informática na Educação: teoria e prática, volume 20, pages 203-218. 